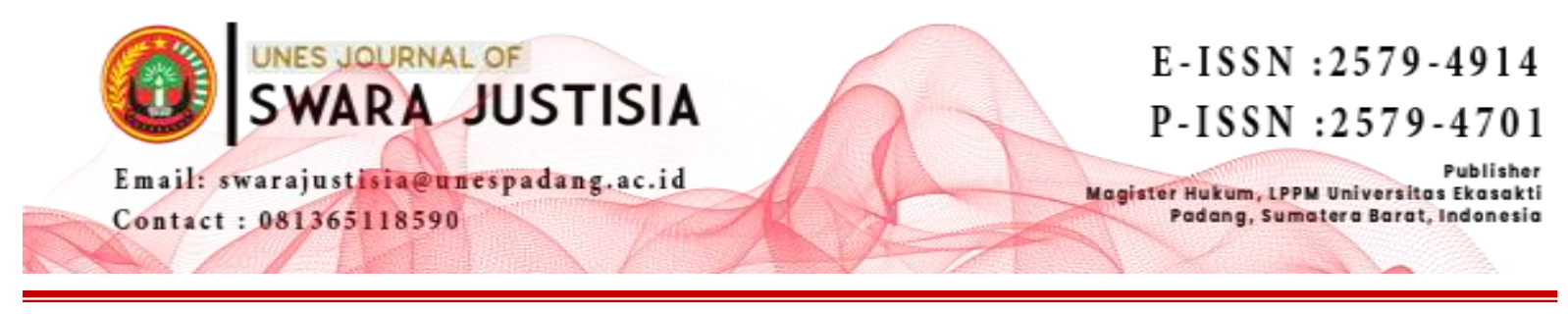

\title{
PELAKSANAAN SERTIFIKASI BAGI DOSEN DALAM RANGKA MEN1NGKATKAN K1NERJA DOSEN (Studi Pada Universitas Ekasakti)
}

\author{
Hary Ardya Nugraha \\ Program Magister Ilmu Hukum,Universitas Ekasakti, Padang \\ Email: haryardya@gmail.com
}

\begin{abstract}
One of the government programs in improving the quality of education is improving the quality of lecturers through lecturer certification. Through the lecturer certification program, professional lecturers will be formed, namely lecturers who at least have met the standards of academic qualifications and competence. Likewise at Ekasakti University, the implementation of the Lecturer certification program has also been running which is divided into several stages, namely D1, D2, D3, D4 and D5. This research focuses on three main issues: First, how is the implementation of lecturer certification at Ekasakti University (UNES)? Second, what are the obstacles faced in the implementation of Lecturer certification at Ekasakti University (UNES) and what efforts are being made to overcome the obstacles that exist in the implementation of Lecturer certification at Ekasakti University (UNES)? This study uses a normative juridical method supported by empirical juridical. The data collection technique used is a field study through interviews for primary data and literature study to find secondary data. The data was then analyzed qualitatively and described in the form of descriptive analysis. Based on the research results, several conclusions were obtained: First, the implementation of lecturer certification at Ekasakti University (UNES) has gone well through the stages, namely DI, D2, D3, D4 and D5. Kedun, the obstacles faced in implementing certification at Ekasakti University (UNES) are the lack of facilities and infrastructure as well as managerial education that has not been maximized, the lecturer's personal ability factor is relatively low, less proficient in using and keeping up with the development of information technology which is growing all the time. to improve capabilities in the field of technology, because in the future any business will be programmed online.
\end{abstract}

Keywords: Lecturer Performance

ABSTRAK
Salah satu program pemerintah dalam meningkatkan kualitas pendidikan adalah peningkatan kualitas dosen melalui sertifikasi dosen. Melalui program sertifikasi dosen, akan terbentuk dosen profesional, yaitu dosen yang minimal telah memenuhi standar kualifikasi akademik dan kompetensi. Demikian halnya di Universitas Ekasakti, pelaksanaan program sertifikasi Dosen juga sudah berjalan yang dibagi dalam beberapa tahap, yaitu D1, D2, D3, D4 dan D5 Penelitian ini $\mathrm{mG}$ 1<kberatkan kepada tiga pokok permasalahar: Pertcma, Bagaimana pelaksanaan sertifikasi dosen di Universitas Ekasakti (UNES)? Kedua, Apa saja kendala yang dihadapi dalam pelaksanaan sertifikasi Dosen di Universitas Ekasakti (UNES) dan upaya apa saja yang dilakukan untuk mengatasi kendala yang ada dalam pelaksanaan sertilikasi Dosen di Universitas Ekasakti (UNES)? Penelitian ini menggunakan metode yuridis normatif 
didukung yuridis empiri. Teknik pengum.pulan data yang digunakan a.dalah studi lapangan melalui wawancara untuk data primer dan studi kepustakaan untuk mencari data sekunder. Data tersebut kemudian dianalisis secara kualitatif dan diuraikan dalam bentuk deskriptif analisis. Berdasarkan hasii penelitian diperoieh beberapa kesimpulan : Pertama, pelaksanaan sertifikasi dosen di Universitas Ekasakti (UNES) sudah beijalan dengan baik melalui tahap, yaitu DI, D2, D3, D4 dan D5. kedun, kendala yang dihadapi dalam pelaksanaan sertifikasi di Universitas Ekasakti (UNES) adalah minimnya sarana dan prasarana serta manajerial bidang pendidikan yang belum maksimal, faktor kemampuan personal Dosen yang relatif rendah, kurang mahir menggunakan dan mengikuti perkembangan teknologi informasi yang setiap saat makin berkembang, ciiharapkan untuk meningkatKan kemampuan di bidang teknologi, karena ke depan urusan apapun akan di program secara online.

\section{Kata Kunci: Kinerja Dosen}

\section{PENDAHULUAN}

Pendidikan adalah fondasi dasar suatu bangsa. Kualitas pendidikan yang baik merupakan cerminan dari kualitas suatu bangsa. Sebagaimana disebutkan dalam Pembukaan UUD 1945 bahwa tujuan nasional bangsa Indonesia adalah untuk melindungi segenap bangsa dan seluruh tumpah darah Indonesia dan untuk memajukan kesejahteraan umum, mencerdaskan kehidupan bangsa dan ikut melaksanakan ketertiban dunia berdasarkan kemerdekaan, perdamaian abadi dan keadilan sosial.Untuk mewujudkan tujuan nasional tersebut, pendidikan merupakan faktor yang sangat menentukan, Pendidikan yang bermutu sangat tergantung pada kapasitas agen-agen pendidikan dalam mentranformasikan peserta didik untuk memperoleh nilai tambah, baik yang terkait dengan aspek olah pikir, rasa, hati, dan raganya. Dari sekian banyak komponen pendidikan, Dosendan dosen merupakan faktor yang sangat penting dan strategis dalam usaha meningkatkan mutu pendidikan di setiap satuan pendidikan.

Dalam rangka mewujudkan tujuan pendidikan nasional tentunya peranan tenaga pendidik atau dosen sangatlah penting, karena berfungsi sebagai ujung tombak dalam kegiatan pendidikan ini. Mengingat pentingnya peranan dosen dalam proses menciptakan sumber daya manusia yang berkualitas, maka dosen yang akan mengajar harus memiliki beberapa persyaratan yang telah ditentukan oleh undang-undang, Berdasarkan UndangUndang Nomor 14 Tahun 2005 tentang Guru dan Dosen, menyatakan bahwa dosen wajib memiliki kualifikasi akademik, kompetensi, sertifikat pendidik, sehat jasmani dan rohani, dan memenuhi kualifikasi lain yang dipersyaratkan satuan pendidikan tinggi tempat bertugas, serta memiliki kemampuan untuk mewujudkan tujuan pendidikan nasional.

Faktor utama rendahnya mutu pendidikan adalah kondisi pengajar atau pendidik yang kualifikasinya tidak layak atau mengajamya tidak sesuai bidang keahliannya, Tantangan yang terkait dengan mutu pendidik mencakup tantangan kompetensional pribadi maupun keterampilan pendidik dalam melaksanakn tugasnya, Kompetensi adalah suatu kemampuan untuk melaksanakan suatu pekerjaan atau tugas yang dilandasi atas keterampilan dan pengetahuan serta didukung oleh sikap kerja yang dituntut oleh pekerjaan tersebut, Kompetensi adalah karakteristik dasar dari seseorang yang memungkinkan pegawai mengeluarkan kinerja superior dalam pekerjaannya, ${ }^{1}$ Di dalam UU RI Nomor 14 Tahun 2005

\footnotetext{
${ }^{1}$ Wibowo, Manajemen Kinerja, Edisi keempat, Jakarta : Rajawali Pers, 20J 4,hlm. 110
} 
Pasal 1 ayat (10) dijelaskan bahwa Kompetensi adalah seperangkat pengetahuan, keterampilan, dan perilaku yang harus dimiliki, dihayati, dan dikuasai oleh guru atau dosen dalam melaksanakan tugas keprofesionalan.

Perlu upaya untuk memperbaiki kualitas pendidikan tinggi di Indonesia pada umumnya dan perguruan tinggi swasta di Kopertis Wilayah X Padang pada khususnya, Diperlukan perbaikan yang menyeluruh terhadap unsur-unsur yang saling terkait di dalamnya, Salah satu unsur yang mempunyai peranan sangat penting dalam meningkatkan kualitas pendidikan tinggi tersebut adalah tenaga pendidik, dalam hal ini adalah dosen.

Dosen merupakan salah satu komponen esensial dalam suatu sistem pendidikan di perguruan tinggi, Peran, tugas, dan tanggungjawab dosen sangat bermakna dalam mewujudkan tujuan pendidikan nasional, yaitu mencerdaskan kehidupan bangsa, meningkatkan kualitas manusia Indonesia, meliputi kualitas iman dan takwa, akhlak mulia, dan penguasaan ilmu pengetahuan, teknologi, dan sent, serta mewujudkan masyarakat Indonesia yang maju, adil, makmur, dan beradab.

Kinerja adalah sesuatu yang dicapai atau prestasi yang diperlihatkan atau kemampuan bekerja, dengan kata lain bahwa kinerja dapat diartikan sebagai prestasi kerja, Jika kinerja adalah kuantitas dan kualitas pekerjaan yang diselesaikan oleh individu, maka kinerja merupakan output pelaksanaan tugas, Kineija mempunyai hubungan erat dengan masalah produktivitas, karena merupakan indikator dalam menetukan bagaimana usaha untuk mencapai tingkat produktivitas yang tinggi dalam suatu organisasi. ${ }^{2}$

Universitas Ekasakti merupakan salah satu Perguruan Tinggi Swasta yang ada di Kota Padang, Melihat perkembangan dan perubahan yang lebih mengarah kepada visi Universitas, maka sangat perlu dilakukan penataan Sumber Daya Manusia sebagai tenaga pendidik yang bermutu,Dengan demikian untuk menganalisis pelaksanaan implikasi sertifikasi dosen dan mengetahui kendala dan upaya yang pernah dialami dosen Universitas Ekasakti, Tenaga pendidik hendaknya memilki kualifikasi akademik yaitu minimal lulusan Magister sesuai dengan bidang keahlian dan memiliki kompetensi sebagai ruh dari pelaksanaan Tri Darma Perguruan Tinggi, Kualitas mutu lulusan yang dihasilkan tidak terlepas oleh kualitas proses pembelajaran melalui kinerja dosen yang ada di Universitas Ekasakti.

Berdasarkan pemaparan di atas, maka dalam penulisan ini penulis tertarik untuk membahas tentang: "Pelaksanaan Sertifikasi Bagi Dosen Dalam Rangka Meningkatkan Kinerja Dosen (Study Pada Universitas Ekasakti)".

\section{METODE PENELITIAN}

Tipe dari penelitian ini adalah merupakan penelitian deskriptif analisis, Penelitian deskriptif adalah suatu bentuk penelitian yang paling dasar, Ditujukan untuk mendesripsikan atau menggambarkan fenomena-fenomena yang ada, baik fenomena yang bersifat alamiah ataupun rekayasa manusia, Penelitian ini mengkaji bentuk aklivitas, karakteristik, perubahan, hubungan, kesamaan, dan perbedaannya dengan fenomena lain. ${ }^{3}$ Dengan demikian, penelitian deskriptif disini dimaksudkan untuk memberikan data dan gambaran terhadap masalah yang

${ }^{2}$ Bakar, Usman Abu, Pengantar Manajemen Sumber Daya Manusia dalam Persfektif Pendidikan Islam, Surakarta: Fataba Press, 2014, hlm.103

3 Na.ma Syaodih Sukmadinata, Metode Penielitian Pendikan, PT, Remaja Rosda Karyn Cetakan Keenam, 2010, htm. 72 
diteliti baik keadaan atau gejala-gejala maupun akibatnya, yakni tentang implementasi yuridis sertifikasi dosen terhadap kin erja dosen di Universitas Ekasakti.

Metode pendekatan yang digunakan dalam penelitian ini adalah yuridis normatif yang didukung oleh yurids empiris, Pendekatan yuridis normatif digunakan untuk menguraikan bahan-bahan kepustakaan berupa peraturan perundang-undangan,buku-bukudanhasi1 penelitian yang terkait dengan implementasi yuridis Sertifikasi dosen terhadap kineija dosen di Universitas Ekasakti, Sedangkan pendekatan yuridis empiris memergunakan data primer yang berhubungan dengan implementasi yuridis Sertifikasi doseri terhadap kinerja dosen di Universitas Ekasakti.

\section{PEMBAHASAN}

\section{A. Pelaksanaan Sertifikasi Dosen di Lingkungan Universitas Ekasakti}

Pada bagan struktur organisasi di atas, terlihat bahwa Universitas Ekasakti dipimpin oleh seorang Ketua Yayasan, yang dalam pelaksanaan tugasnya sehari hari Ketua Yayasan dibantu oleh Rektor, Wakil Rektor I, Wakil Rektor II dan Wakil Rektor III. Wakil Rektor II dibantu oleh beberapa bagian, yaitu :

1. Biro Administrasi Umum dan Keuangan (BauK)

2. Badan Pengembangan Sistem Informasi (BAPSI)

Pada pelaksanaan kegiatan sertifikasi dosen, lebih banyak melibatkan bagian kepegawaian dan kelembagaan. Karena berhubungan dengan permasalahan data base dosen dan pelaporan data Perguruan Tinggi Swasta ke Dikti. Berdasarkan hasil penelitian penulis pada Dosen Universitas Ekasakti, diketahui bahwa pelaksanaan serdos di lingkungan Universitas Ekasakti dilakukan melalui beberapa tahapan :

Tahap I Dosen Melengkapi Data yang terdiri dari :

a. Jafung

b. Kepangkatan

c. Data profil 2x Kartu Keluarga dan NPWP

d. Pendidikan Formal

e. Penelitian

f. Pengabdian

g. Kegiatan Penujang Lainnya

1. Edigible (D1)

a. Data yang perlu disiapkan sebelum pelaksanaan serdos, syarat masuk data DI (eligible) yaitu :data yang berkaitan dengan track record dosen, misal data Jabatan Akademik, Kualifikasi Pendidikan, Kepangkatan/lnpassing, Homebase, masa kerja, dll.

b. Sistem/Laman yang digunakan pada pelaksanaan Serdos adalah menggunakan Aplikasi SISTER, dengan laman/alamat web untuk Perguruan Tinggi.

c. Cara memperoleh Akun pada aplikasi Sister, dengan cara Dosen mendaftar mandiri melalui SISTER PT dengan memasukkan NIDN dan alamat email aktif.

d. Cara memperoleh informasi terkait pelaksanaan, jadwal dan buku pedoman pelaksanaan Serdos dengan mengakses laman resmi informasi pelaksanaan sertifikasi pendidik untuk dosen. 
e. Masa berlaku Sertifikat/Skor TKBI dan TKDA untuk pelaksanaan Serdos adalah khusus untuk penilaian serdos, semua skor TKBI/TKDA tidak dipengaruhi oleh masa berlaku yang tertulis disertifikat, (berlaku selamanya)

f. Cara melihat daftar data d1 PTU ?

g. Jawab yaitu melalui akun PSD PTU, data daftar eligible D 1 dapat dilihat melalui menu manajemen serdos, kemudian klik daftar D1 Eligible : melalui akun dosen, pilih menu layanan serdos.

h. Cara mengecek penyebab tidak masuk Dafiar Eligible dengan melalui akun PSD PTU, melalui menu manajemen serdos, diklik tombol "mengapa tidak masuk Dl?", kemudian masukkan nidn/nidk yang akan cek, maka akan tampil data dosen tersebut, dan cart data yang berwama merah, itulah data yang masih kurang, dan agar segera diperbaiki dan diupdate data yang kurang tersebut.

\section{Data D2}

Yaitu menentukan Kopertis dengan tugas sebagai berikut :

a. Mengkoordinasikan calon DYS dari PTU PTS dilingkungan wilayahnya

b. Menjadi PTU bagi PTS dengan DYS kurang dari 5 orang

c. Menyosialisasikan prosedur dan proses berdasarkan buku panduan sertifikasi dosen (Buku-1, Buku-2, dan Buku-3)

d. Melakukan validasi DYS di wilayahnya

\section{Data D3}

Universitas Ekasakti melakukan Verifikasi data (PTPS) diantaranya bidang ilmu dan mengusulkan Dosen untuk mnengikuti Serdos dan mengupload surat Pemyataan dari Pimpinan.

\section{Data D4}

a. Penilaian Nilai Gabungan Dosen Serdos

b. Perhitungan NGB Serdos

\section{Data DS (pengisian deskripsi diri)}

Penilaian deskripsi diri tidak berhubungan dengan nilai Gabungan NGB, dinilai secara terpisah namun berpengaruh terhadap Penilaian Konsistensi yang memiliki dua elemen berupa: Hasil penilaian persepsional dan Hasil Penilaian Deskripsi Diri. Dari seluruh elemen penilaian yang ada di sertifikasi dosen, hanya elemen penilaian Deskripsi Diri ini yang sulit diprediksi hasilnya, bahkan setelah pengumuman kelulusan diterbitkan, elemen penilaian ini tidak diketahui pencapaiannya. Kedepannya perlu dipertimbangkan oleh DIKTI agar hasil dari penilaian diri oleh Asesor dapat diberikan kembali kepada DYS (sebagai bahan masukan andai DYS dinyatakan tidak lulus, layaknya seorang dosen yang memberikan hasil ujian kepada mahasiswa yang disertai dengan catatan-catatan perbaikan). Seorang DYS dinyatakan lulus jika Nilai Akhir deskripsi diri dari kedua asesor (NADD) > 4, yang termasuk ke dalam katagori "Sedang" dengan prosentase $57,14 \%$. Sehingga sudah dapat dipastikan jika Nilai NADD tidak boleh berada di katagori rendah, karena pasti tidak akan lulus.

\section{Kelulusan (Yudisium Serdos)}

a. DYS dapat melihat hasil pengumuman kelulusan serdos setelah diadakan Yudisium Nasional. 
b. DYS dapat melihat hasil pengumuman kelulusan serdos dengan melalui sister.kemdikbud.go.id dengan akun masing-masing DYS

c. Cara DYS mendapatkan Sertifikat Pendidik, setelah dinyatakan lulus, setelah Sertifikat Pendidik dicetak dan ditandatangani oleh Pemimpin PTPS, selanjutnya sertifikat tersebut dikirim ke PTU/LLDikti. Apabila PTPS sudah mengunggah scan dokumen sertifikat pendidik DYS dapat mengunduh dokumen tersebut melalui akun DYS.

\section{PENUTUP}

Berdasarkan uraian pada bab bab sebelumnya, dari hasil penelitian penulis ini dapat disimpulkan sebagai berikut :

1. Pelaksanaan sertifikasi dosen di lingkungan Universitas Ekasakti sudah dilakukan sesuai dengan ketentuan perundang undangan yang berlaku. Sejak tahun pertama dengan menggunakan sistem manual dengan pengiriman bahan oleh dosen kepada asesor pada perguruan tinggi penyelenggara, sampai pada sistem online yang sudah diterapkan pada beberapa tahun terakhir. Dimana peserta hanya mengupload data yang harus di isi melalui website dikti, kemudian juga mengisi dan mengirimkan secara online langsung melalui web dikti.kopertis sebagai kepanjangan tangan Dikti membantu proses pelaksanaan serdos PNS yang diperbantukan dan Dosen tetap yayasan yang berada di lingkungan Unes. Pada prosesnya pelaksanaan sertifikasi dosen lingkungan Unes dilakukan melalui 3 tahap, mulai dari pengisian data, pengecekan data dan menunggu hasil lulus dan tidaknya berhasil lulus sertifikasi.

2. Pelaksanaan serdos yang sudah diberikan terhadap 94 orang dosen di lingkungan Unes sampai tahun 2017 (terdiri dari dosen PNSD 43 orang dan 51 orang dosen Yayasan) secara umum terlihat dalam 3 (tiga) hal mendasar yaitu peningkatan kesejahteraan dosen yang menerima dana sertifikasi, peningkatan kuliatas dosen penerima serdos serta peningkatan mutu lulusan Perguruan Tinggi itu sendiri. Sedangkan mengenai tingkat pencapaian dari ketiga pelaksanaan ini memerlukan penelitian lebih lanjut.

3. Kendala kendala yang ditemui oleh Unes dalam melaksanakan serdos masih beragam, namun yang paling prinsip adalah karena masi banyaknya dosen yang belum valid melakukan verivikasi data EPSBED, sehingga masi banyak dosen yang seharusnya sudah masuk kouta penerimaan serdos, karena data mereka belum divalidasi oleh PTS. Selain itu ditemukan kendala kendala yang bersifat teknis, seperti masi banyaknya dosen yang gaptek terhadap teknologi sedangkan zaman sekarang diperlukan tanggap teknologi.

4. Upaya yang dilakukan oleh Unes untuk mengatasi kendala yang ada dalam pelaksanaan sertifikasi dosen antara lain, mengadakan sosialisasi tentang sertifikasi dosen dengan mengundang dosen dosen yang akan mengikuti serdos untuk segera mengurus persyaratan SK Inpassing dosen dan mengirimkannya ke Kopertis, supaya dapat segera di proses, meminta kepada PTS untuk segera membalas surat yang dikirim Kopertis baik kepada Pimpinan PTS maupun kepada dosen yang bersangkutan, melaksanakan pelatihan pemgisian data dan upload data sertifikasi melalui website dikti kepada dosen dosen Unes serta membantu memantau dan menginformasikan kepada dosen melalui 
Operator Unes, tentang valid tidaknya data yang diisikan dosen selama proses validasi data.meluangkan waktu.

\section{REFERENSI}

Wibowo, Manajemen Kinerja, Edisi keempat, Jakarta : Rajawali Pers, 2014

Bakar, Usman Abu, Pengantar Manajemen Sumber Daya Manusia dalam Persfektif Pendidikan Islam, Surakarta: Fataba Press, 2014

Nana Syaodih Sukmadinata, Metode Penielitian Pendikan, PT, Remaja Rosda Karyn Cetakan Keenam, 2010

Undang-Undang Dasar Negara Republik Indonesia Tahun 1945.

Undang-Undang Republik Indonesia Nomor 20 Tahun 2003 tentang Sistem Pendidikan Nasional.

Undang-Undang Republik Indonesia Nomor 32 Tahun 2004 tentang Pemerintah Daerah. Undang-Undang Republik Indonesia Nomor 14 Tahun 2005 tentang Guru dan Dosen.

Peraturan Pemerintah Republik Indonesia Nomor 25 Tahun 2000 tentang Kewenangan Pemerintah dan Kewenangan Propinsi Sebagai Daerah

Peraturan Pemerintah Republik Indonesia Nomor 19 Tahun 2005 tentang Standar Nasional Pendidikan. 